\title{
Investigation of Social Appearance Concerns of University Students
}

\author{
Fatih Kırkbir (Corresponding author) \\ Physical Education Department, Karadeniz Technical University, Trabzon, Turkey \\ E-mail: fatihkirkbir@gmail.com
}

\author{
Samet Zengin \\ Faculty of Sport Sciences, Trabzon University, Trabzon, Turkey \\ E-mail: sametzengin@trabzon.edu.tr
}

Received: January 24, 2022 Accepted: February 23, 2022 Published: March 4, 2022

doi:10.5296/jei.v8i1.19497ＵRL: https://doi.org/10.5296/jei.v8i1.19497

\begin{abstract}
Social appearance concern is very important situation for all people's life. Recently, this situation has revealed similar situations among university students. People exist in a social environment from people's existence. For the fact that, people make an effort to impose themselves in their social environment and it is inevitable that the situation will cause anxiety. From this point of the view, in this study, the social appearance anxiety of the students studying at Karadeniz Technical University was investigated according to some variables. In this direction, a total of 176 students, 73 females and 103 males, from Karadeniz Technical University participated in the study. The Social Appearance Anxiety scale developed by Doğan (2010) was applied to the students participating in the study. The study is a descriptive and the -test one-way analysis of variance and correlation tests were used. According to the results of the findings obtained in the research, it was determined that the participants had a low level of social appearance anxiety. Besides, it was determined that difference between gender and class were significant. On the other hand, there were any significant difference was found in other variables.
\end{abstract}

Keywords: Social appearance, Anxiety, Self-confidence

\section{Introduction}

Human is social being. For this reason, human wants to establish communication with other people in his environment. This situation reveals such factors as looking more attractive and 
willing to communicate with people more (Yousefi, Hassani, \& Shokri, 2009). According to the literature, it is stated that the person has positive and negative body image. Positive body image is defined as the state of being satisfied with the external appearance of the individual, while negative body image is defined as the state of being dissatisfied with the external appearance of the individual (Doğan, 2010). It is thought that looking attractive, the desire to communicate more with other people, and the appearance of people may cause anxiety in them. In previous research studies, the Social Appearance Anxiety Scale was developed to determine the social appearance anxiety experienced by people (Hart, Leary, \& Rejeski, 1989). Social appearance anxiety is examined, and it is stated that it is a concept that includes more detailed features such as skin color and eye color, as well as height, weight, and muscular characteristics of the person (Hart et al., 2008). In other words, all these variables are effective in social appearance anxiety holistically.

The anxiety of appearance of a person in his social life has attracted the attention of many researchers and many studies have been done about it. In this context, it has been a matter of curiosity to determine the social appearance anxiety of university students. Therefore, it is aimed to reveal the social appearance anxiety of my students studying at Karadeniz Technical University according to some variables.

\section{Method}

In this research, social appearance anxiety levels of students studying at Karadeniz Technical University were investigated according to some variables through a descriptive study. The research was carried out with the relational survey model, which is one of the general survey models (Karasar, 2020).

\subsection{Research Group}

The research group consists of 176 people, 73 females, and 103 males, studying at Karadeniz Technical University in the 2020-2021 academic year.

\subsection{Data Collection Tool}

The social appearance anxiety scale was used as a data collection tool in the study. The scale, developed by Hart et al. and adapted into Turkish by Doğan, has a single factor structure. The scale, consisting of 16 items, is scored in a 5-point Likert type. The internal consistency coefficient of the scale calculated within the scope of this study is 0.94 .

\subsection{Data Analysis}

In the analysis of the data collected within the scope of the study, descriptive statistical methods, T-test, one-way analysis of variance, and correlation tests were used by using SPSS 23.0 program. 


\section{Findings}

Table 1. Score distribution

\begin{tabular}{|l|l|l|l|l|l|l|l|l|}
\hline & Items Number & $\mathbf{n}$ & Avg. & Ss. & Skewness & Kurtosis & Max. & Min. \\
\hline SAAS & 16 & 176 & 2.03 & 0.90 & 1.26 & 0.83 & 1.00 & 4.70 \\
\hline
\end{tabular}

When we look at the distribution of the scores of the participants from the Social Appearance Anxiety Scale, it is seen that the arithmetic mean of the scores of the students from the scale is 2.03 , and the standard deviation is 0.90 . In addition, when the skewness and kurtosis values of the scores obtained from the scales are examined, it can be said that the data show a normal distribution, so it is appropriate for the analysis.

Table 2. T-test results based on gender variable

\begin{tabular}{|c|c|c|c|c|c|}
\hline & \multicolumn{2}{|c|}{ Woman (73) } & \multicolumn{2}{|c|}{ Man (103) } & \multirow{2}{*}{ p } \\
\hline & Avg. & Ss. & Avg. & Ss. & \\
\hline SAAS & 1.80 & 0.75 & 2.05 & 0.95 & 0.03 \\
\hline
\end{tabular}

Note. $* \mathrm{p}<0.05$.

When the T-test results of the Social Appearance Anxiety Scale based on Gender Variable were examined, it was seen that the difference between gender was significant.

Table 3. Anova results based on class variable

\begin{tabular}{|l|l|l|l|l|l|l|l|l|}
\hline \multicolumn{2}{|c|}{ 1 (n= 50) } & \multicolumn{2}{c|}{ 2 (n= 40) } & \multicolumn{2}{c|}{ 3(n= 40) } & \multicolumn{2}{c|}{ 4 (n= 46) } & \multirow{2}{*}{ p } \\
\cline { 1 - 8 } Avg. & Ss. & Avg. & Ss. & Avg. & Ss. & Avg. & Ss. & \\
\hline $\mathbf{2 . 0 2}$ & 0.75 & 1.95 & 0.80 & 1.88 & 0.78 & 2.04 & 0.80 & $\mathbf{0 . 3 3}$ \\
\hline
\end{tabular}

Note. $* \mathrm{p}<0.05$.

When the Anova results of the Social Opinion Anxiety Scale by Class Variable were examined, no significant difference was found. 
Table 4. Relationship results between scale score and age

\begin{tabular}{|l|l|l|l|}
\hline & $\mathbf{n}$ & $\mathbf{r}$ & $\mathbf{p}$ \\
\hline Scale-Age & 176 & 0.03 & 0.70 \\
\hline
\end{tabular}

When Table 4 is examined, no significant relationship was found as a result of the relationship between the scale score distribution of the participants and age.

\section{Discussion}

In this section, the findings related to the gender, age, and class variables of social appearance anxiety of university students studying at Karadeniz Technical University were investigated, interpreted, and suggestion were made.

In our study, social appearance anxiety showed differences according to the gender variable. While it is noteworthy that social appearance anxiety is higher in male participants, this difference is thought to be related to the study group. When the literature was examined, different results were seen. Although there are studies in the literature that support our study (Tiegman, 2004; Moreno \& Cervello, 2005; Alemdağ, 2013; Kılıç \& Karakuş, 2016), there are also studies stating that female participants have more social appearance anxiety (Hagger \& Stevenson, 2010; Alımc1, 2018).

In our study, no significant difference was found between the social appearance anxiety scale score and the age variable. When we examine the information obtained from the literature, some studies indicate that when the age factor increases, social appearance anxiety decreases (Schneier et al., 1992; Kessler et al., 2005). It is indicated that the studies do not show similarities with our study. It is thought that the increase in the number of study group may also create different results.

In the study, social appearance anxiety did not show a significant difference according to the class variable. When the literature is examined, it is stated that social appearance anxiety changes according to the class variable (Baltac1, 2010; Y1ldırım et al., 2011; Witchen \& Fehm, 2003). The reason why our study gave different results is thought to be related to the sample group.

\section{Conclusion}

- According to the results of the findings obtained in the research, the social appearance anxiety of the participants is low.

- According to the scores obtained from the social appearance anxiety scale, it was seen that male participants had higher social appearance anxiety.

- According to the scores obtained from the social appearance anxiety scale, no significant difference was found according to the class variable of the participants.

- According to the scores obtained from the social appearance anxiety scale, it was seen that 
there was no significant difference between the age variable of the participants.

By the way, we want to give some suggestions to the literature and any other writer about this topic after this time who wants to investigate this kind of topics.

- It is possible to work with a larger sample group by increasing the number of participants.

- Groups can be compared by performing the same study on students studying at different universities.

- The study can be done with different groups and results in other fields can be revealed.

- The study can be examined in detail by backing up with qualitative research methods.

\section{References}

Alemdağ, S. (2013). Examination of the relationship between participation in physical activity, social appearance anxiety and social self-efficacy in teacher candidates (Unpublished Doctoral thesis, Karadeniz Technical University, Trabzon).

Alımc1, D. (2018). Investigation of the relationship between peer bullying and social appearance concerns of secondary school students and their self-esteem (Unpublished Master's thesis, İstanbul Sabahattin Zaim University, İstanbul).

Baltac1, Ö. (2010). Examining the relationship between university students' social anxiety, social support and problem solving approaches (Unpublished Master's thesis, Selçuk University, Kenya).

Doğan, T. (2010). Turkish version of the Social Appearance Anxiety Inventory (SSS): Validity and reliability study. Journal of Hacettepe University Faculty of Education, 39(39), 151-159.

Hagger, S. M., \& Stevenson, A. (2010). Social physique anxiety and physical self-esteem: Gender and age effects. Psychol and Health, 25(1), 89-110. https://doi.org/10.1080/ 08870440903160990

Hart, E. A., Leary, M. R., \& Rejeski, W. J. (1989). The measurement of social physique anxiety. Journal of Sport and Exercise Psychology, 11, 94-104. https://doi.org/10.1123/ jsep.11.1.94

Hart, T. A., Flora, D. B., Palyo, S. A., Fresco, D. M., Holle, C., \& Heimberg, R. G. (2008). Development and examination of ehe social appearance anxiety scale. Assessment, 15(1), 48-59. https://doi.org/10.1177/1073191107306673

Karasar, N. (2020). Scientific Research Method: Concepts, Principles, Techniques. Ankara: Nobel Publishing.

Kessler, R. C., Berglund, P., Demler, O., Jin, R., \& Walters, E. E. (2005). Life time prevalence and age of onset distributions of DSM-IV disorders in the national comorbidity survey replication. Archives in General Psychiatry, 62, 593-602. https://doi.org/10.1001/ archpsyc.62.6.593 


\section{Macrothink}

Kılıç, M., \& Karakuş, Ö. (2016). Examining the relationship between university students' social appearance anxiety, self-esteem and loneliness levels. Journal of Human Sciences, 13(3), 3837-3852. https://doi.org/10.14687/jhs.v13i3.4054

Moreno, J. A., \& Cervelló, E. (2005). Physical self-perception in spanish adolescents: Effects of gender and involvent in physical activity. Journal of Human Movement Studies, 48, 291-311.

Schneier, F. R., Johnson, J., Hornig, C. D., Liebowitz, M. R., \& Weissman, M. M. (1992). Social anxiety: Comorbidity and morbidity in an epidemiologic sample. Archives of General Psychiatry, 49, 282-288. https://doi.org/10.1001/archpsyc.1992.01820040034004

Tiggemann, M. (2004). Media influences on body image development. In T. F. Cash \& T. Pruzinsky (Eds.), Body Image a Handbook of Theory, Research and Clinical Practice (pp. 91-98). New York: The Guilford Press

Wittchen, H. U., \& Fehm, L. (2003). Epidemiology and natural course of social fears and phobia. Acta Psychiatr Scand, 103(Supl. 417), 4-18. https://doi.org/10.1034/j.1600-0447. 108.s417.1.x

Yıldırım, T., Çırak, Y., \& Konan, N. (2011). Social anxiety in teacher candidates. Journal of Inönü University Faculty of Education, 12(1), 85-100.

Yousefi, B., Hassani, Z., \& Shokri, O. (2009). Reliability and factor validity of the 7- Item Social Physique Anxiety Scale (SPAS-7) among university students in Iran. World Journal of Sport Sciences, 2(3), 201-204.

\section{Copyright Disclaimer}

Copyright for this article is retained by the author(s), with first publication rights granted to the journal.

This is an open-access article distributed under the terms and conditions of the Creative Commons Attribution license (http://creativecommons.org/licenses/by/3.0/). 